\title{
MIGRAÇÃO INTERNACIONAL: ENSAIO SOBRE O FLUXO DE MEDICAMENTOS E PLANTAS MEDICINAIS PARA BRASILEIROS NO EXTERIOR $^{1}$
}

\section{INTERNATIONAL MIGRATION: ESSAY ON THE FLOWS OF MEDICINES AND MEDICINAL PLANTS TO BRAZILIANS ABROAD}

\author{
Viviane Kraieski de Assunção ${ }^{2}$
}

\begin{abstract}
RESUMO
Este artigo baseia-se em dados de duas pesquisas etnográficas realizadas com imigrantes brasileiros nos Estados Unidos e na Holanda. O trabalho de campo evidenciou a recorrência de fluxos de medicamentos, plantas medicinais e saberes relacionados ao tratamento de doenças entre imigrantes brasileiros e seus familiares, parentes e amigos que permaneceram no Brasil. O artigo explora duas possibilidades interpretativas destes fluxos: (1) compreender esta circulação como formas de manutenção e fortalecimento de laços sociais entre os indivíduos que migraram e aqueles que permaneceram no Brasil; (2) utilizando-se a obra de Tim Ingold, entender como estes conhecimentos dos imigrantes são constantemente (re)construídos e atualizados através da prática.
\end{abstract}

PALAVRAS-CHAVE: Imigrantes brasileiros, conhecimentos tradicionais, plantas medicinais

\begin{abstract}
This article is based on data from two ethnographic research conducted with Brazilian immigrants in the United States and the Netherlands. Fieldwork data showed the recurrence of flows of medicines, medicinal plants and knowledge related to the treatment of diseases among Brazilian immigrants and their family members, relatives and friends who remained in Brazil. The article explores two possible interpretations of these flows: (1) to understand this movement as ways of maintaining and strengthening social ties among individuals who migrated and those who remained in Brazil; (2) using the work of Tim Ingold, to understand how these skills of immigrants are constantly (re)built and updated through practice.
\end{abstract}

KEYWORDS: Brazilian immigrants, traditional knowledge, medicinal plants

\footnotetext{
${ }^{1}$ Este artigo é uma versão de uma apresentação da autora na mesa redonda sobre conhecimentos tradicionais na VII Jornada Catarinense de Plantas Medicinais, realizada de 25 a 28 de agosto de 2014, no campus da UNESC (Universidade do Extremo Sul Catarinense), Criciúma, SC.

${ }^{2}$ Professora do Programa de Pós-Graduação em Ciências Ambientais (PPGCA) da Universidade do Extremo Sul Catarinense (UNESC).
} 


\section{Introdução}

Os grupos migrantes são estudados por pesquisadores culturais e sociais por possibilitarem a investigação das mudanças e/ou continuidades de diferentes aspectos socioculturais. Diversos estudos afirmam que, quando migram, os indivíduos levam consigo práticas e saberes oriundos de seu contexto sociocultural e de suas trajetórias de vida, que podem ser modificados e/ou mantidos na sociedade de chegada. Assim, a migração levaria os indivíduos a um processo de interpenetração (BASTIDE, 1956), ou seja, os imigrantes associariam sua cultura de partida com a cultura do país onde vivem. Deste modo, ao mesmo tempo em que adotam elementos desta outra cultura, reproduzem seu próprio significado de acordo com as lógicas de sua cultura de origem, mas também com a estrutura social das sociedades de chegada.

Dentre estas práticas e saberes, podem ser destacados os cuidados com o corpo, mais precisamente, os conhecimentos em relação à saúde e doença. Este artigo baseia-se em pesquisas etnográficas realizadas com imigrantes brasileiros nos Estados Unidos e na Holanda. Durante o trabalho de campo nos dois países, foi identificada a recorrência de um fluxo de medicamentos, plantas medicinais e outros produtos destinados ao tratamento de doenças e males do corpo. Estes eram enviados por indivíduos no Brasil para seus familiares, parentes ou amigos que migraram para o exterior.

Estes dados de campo são aqui compreendidos a partir de duas perspectivas teóricas. Primeiro, estes fluxos de medicamentos, plantas medicinais e saberes são relacionados a formas de manutenção e fortalecimento de laços sociais entre os imigrantes no exterior e seus familiares, parentes e amigos que permaneceram no Brasil. Posteriormente, utiliza-se a obra de Tim Ingold para entender como estes conhecimentos dos imigrantes são constantemente (re)construídos e atualizados através da prática cotidiana. Não se trata aqui de atestar a eficácia destes conhecimentos nem de esgotar suas possibilidades interpretativas, mas de oferecer uma análise sobre estes fluxos de bens e saberes que acompanham o fenômeno migratório de diversos grupos sociais.

\section{Percursos metodológicos}


Os dados presentes neste artigo se derivam de duas pesquisas etnográficas (CARDOSO DE OLIVEIRA, 1998; PEIRANO, 1995) realizadas com imigrantes brasileiros no exterior em dois momentos distintos. A primeira, no ano de 2009, durante a realização de trabalho de campo com imigrantes brasileiros na Grande Boston, nos Estados Unidos. Já em 2012, foi realizada uma pesquisa etnográfica com imigrantes brasileiros na Holanda. Nos dois momentos, a pesquisa etnográfica abrangeu um contingente heterogêneo: os sujeitos da pesquisa eram provenientes de diferentes Estados brasileiros, faixas etárias (variando de 18 a 75 anos) e níveis educacionais (desde brasileiros com pouca educação formal até aqueles que concluíram o ensino superior). Nas duas pesquisas etnográficas, foi privilegiada a participação (ASSUNÇÃO, 2014) da pesquisadora em atividades cotidianas com seus sujeitos de pesquisa, além da realização de entrevistas em profundidade com, pelo menos, 20 (vinte) indivíduos em cada um dos contextos mencionados. Neste artigo, todos os nomes dos sujeitos da pesquisa foram substituídos por nomes fictícios como forma de garantir seu anonimato.

Nos Estados Unidos, os interlocutores ${ }^{3}$ da pesquisa tinham também diferentes tempos de permanência e status migratório - desde brasileiros indocumentados, com visto de estudantes, Green Card (residente permanente legal) e até mesmo com dupla cidadania (brasileira e norte-americana), mas os lá que viviam ilegalmente e que tinham migrado após o ano 2000 eram visivelmente mais numerosos. Estes brasileiros tinham em comum o fato de terem ido para os Estados Unidos a partir do contato e de informações de outros brasileiros, com quem tinham laços de parentesco ou de amizade, o que evidencia que fazem parte de redes sociais (BOYD, 1989, MASSEY, 1990). Ainda que tenha encontrado brasileiros com diferentes motivações para migrar, a maioria tinha ido para os Estados Unidos com a intenção de passar um período de tempo (em torno de quatro anos) e retornar para o país após realizarem seu projeto migratório, como a compra da casa própria, montar um negócio ou pagar os estudos dos filhos.

\footnotetext{
${ }^{3}$ Os participantes da pesquisa são aqui denominados interlocutores por entender que a pesquisa etnográfica é interativa, caracterizada pela dialogicidade entre o pesquisador e os sujeitos da pesquisa (CLIFFORD, 1986; CARDOSO DE OLIVEIRA, 1998).
} 
A pesquisa realizada na Holanda também incluiu sujeitos indocumentados, que tinham migrado para a Europa em busca da realização de um projeto migratório, mas abrangeu também um grande contingente de mulheres brasileiras que migraram em situação de reunificação familiar. Estas eram casadas ou em relacionamento amoroso com homens holandeses, e possuíam visto provisório ou cidadania holandesa. Elas conheceram seus companheiros também de diferentes formas: no Brasil, quando os holandeses foram até lá a negócios ou férias; pela Internet, através de redes sociais ou sites de relacionamento; outras migraram para a Holanda indocumentadas e conheceram seus companheiros no país.

\section{Circulação de produtos e valores sociais}

Durante a realização das pesquisas etnográficas nos Estados Unidos e na Holanda, foi identificado um intenso fluxo de mercadorias em dois sentidos: havia produtos que os imigrantes enviavam para o Brasil, e outros que eles recebiam de familiares, parentes e amigos que permaneceram em seu país de origem. Estes fluxos seguiam uma espécie de padrão. Eram enviados para o Brasil, principalmente, produtos eletrônicos, roupas e bolsas de grife, perfumes e outros cosméticos. Por outro lado, os imigrantes recebiam, com frequência, medicamentos e comida de diversos tipos, desde carnes, frutas, queijos, docinhos de festa, entre outros. ${ }^{4}$

Os medicamentos eram enviados pelos correios ou através de brasileiros vindos do Brasil que transportavam estes produtos em malas. Estes eram familiares, parentes ou amigos dos imigrantes em visita aos Estados Unidos ou à Holanda, ou ainda imigrantes brasileiros documentados. 5

\footnotetext{
${ }^{4}$ As comidas enviadas por familiares para os imigrantes brasileiros nos Estados Unidos foram descritos e analisados em outro momento (ASSUNÇÃO, 2012).

${ }^{5}$ Nos Estados Unidos, os imigrantes brasileiros portadores de Green Card, ou residentes permanentes nos Estados Unidos, recebiam com frequência pedidos de outros imigrantes para trazer estes produtos a cada vez que retornavam à Grande Boston. Estas pessoas são imigrantes legais que, além da permissão de trabalho, têm também a permissão de sair do país por tempo determinado e retornar. Na Holanda, desempenhavam este papel os imigrantes com visto de residência ou que já possuíam cidadania holandesa.
} 
Dentre os medicamentos, eram enviados frequentemente analgésicos e pomadas para dores musculares, medicamentos para gripe e anticoncepcionais.

De acordo os interlocutores da pesquisa, estes medicamentos os ajudariam a tratar problemas de saúde, como dores musculares causadas pelo trabalho exaustivo, sem a necessidade de perder horas de trabalho para consultar médicos, já que muitos deles recebem por hora trabalhada. Além disso, é preciso considerar que nos Estados Unidos e na Holanda boa parte do sistema de saúde é pago pelos usuários e de alto custo, o que dificulta o acesso dos imigrantes a tratamentos.

Já a fiscalização da venda de medicamentos nos dois países é bastante rigorosa e muitos deles, como antibióticos, são vendidos apenas com receitas médicas, a exemplo do que ocorre no Brasil desde 2010. Outros brasileiros contaram que os remédios contra gripe vendidos em farmácias estadunidenses causam bastante sono, o que os impediriam de trabalhar e, portanto, diminuiria seus ganhos. Uma das interlocutoras contou que trabalhava na cozinha de um restaurante e os movimentos repetitivos a causavam fortes dores nos ombros e nas mãos. Por isso, pediu à filha que enviasse do Brasil uma pomada de uso veterinário para aliviar dores musculares.

É preciso, no entanto, também ponderar que havia, entre os imigrantes brasileiros nos Estados Unidos, uma desconfiança em relação à eficiência de remédios vendidos. Cinco interlocutoras, por exemplo, contaram que os anticoncepcionais que compraram em Boston não tinham nenhum efeito, pois não regulavam seus ciclos menstruais.

Entre os brasileiros na Holanda e nos Estados Unidos havia também uma desconfiança em relação ao diagnóstico de médicos estadunidenses e holandeses. Algumas interlocutoras afirmaram que, para os médicos estadunidenses, "não há vermes nos Estados Unidos”. Uma delas relatou que levou remédio de vermes do Brasil para dar ao neto. Em relação aos médicos holandeses, a maioria dos sujeitos da pesquisa costumava reclamar que estes profissionais da saúde não costumavam medicá-los, o que era visto de forma negativa. De acordo com os brasileiros, os médicos holandeses costumavam apenas receitar apenas analgésicos, os "remédios para dor", o que aumentava sua necessidade por trazer do Brasil outros medicamentos que consideravam mais adequados para tratar seus problemas de saúde. Um dos medicamentos que mais desejavam eram os anti-inflamatórios. 
Além de medicamentos, também há o envio de plantas medicinais para o preparo de chás e outros remédios caseiros, como xaropes e garrafadas. Durante a pesquisa de campo, uma brasileira, por exemplo, relatou ter levado mudas de boldo para cultivar em vasos na Holanda para consumo próprio. Há ainda uma intensa circulação de receitas e conhecimentos sobre medicamentos ou outras preparações para saúde. Os imigrantes tinham acesso a esses conhecimentos através de familiares no Brasil, principalmente mães e avós, mas também havia uma troca destes saberes entre os próprios imigrantes, em seus momentos de sociabilidade (SIMMEL, 1983), como festas de aniversário, missas ou cultos em igrejas, ou local de trabalho.

Estas trocas de informações sobre algumas plantas medicinais também envolviam trocas de conhecimento sobre o idioma local. Os sujeitos da pesquisa trocavam informações sobre a tradução em holandês ou em inglês para o nome de alguma destas plantas, para poder encontrá-las nos supermercados ou nas lojas de produtos naturais locais. Alguns sujeitos da pesquisa também participavam de redes sociais sobre brasileiros na Holanda, onde trocavam informações sobre preparação de chás que tivessem efeito calmante, como erva-doce, e, principalmente, efeito emagrecedor, como chá de hibisco.

A partir destas constatações, destacam-se três pontos que podem ser importantes para pensar estes fluxos de pessoas e plantas medicinais e saberes entre os dois países.

Primeiro, é preciso destacar o papel preponderante das mulheres nestas trocas de produtos e saberes. As mulheres são comumente conhecidas como mantenedoras da cultura étnica nas famílias dos imigrantes, desempenhando papéis como preparar comidas étnicas e celebrar datas importantes. De acordo com Anthias (2001, p.34) as mulheres são transmissoras diretas de elementos da etnicidade por conta de seu domínio nas atividades diárias no ambiente doméstico, como o cuidado com as crianças, o que pode ser estendido aos cuidado de saúde de familiares, parentes e outros indivíduos. ${ }^{6}$

\footnotetext{
6 Além disso, pode-se destacar que as mulheres são comumente associadas às "tarefas de cuidado" em diversas sociedades, como o tratamento de doentes e a educação de crianças nas famílias (MOREIRA, 1999; GONÇALVES, 2002; GONÇALVES; SENA, 2001; ROSA, 2003, PEGORARO; CALDANA, 2006). Estudos mostram como profissões caracterizadas como "atividades de mulheres", como enfermagem e magistério, estão relacionadas a esta tarefa de cuidado que ultrapassa as esferas do domínio privado para o público (MOREIRA, 1999).
} 
Segundo, deve-se também considerar que o uso de plantas medicinais e dos remédios caseiros feitos a partir dessas plantas está relacionado a um amplo processo de revalorização de elementos considerados "naturais". Por meio desta positivação, elementos antes estigmatizados por serem considerados "atrasados" ou "ultrapassados" são ressignificados e associados à melhoria da saúde e qualidade de vida. Moradores de centros urbanos parecem procurar elementos que estão associados à pureza, natureza, autenticidade, em oposição aos produtos industrializados relacionados ao modo de vida moderno (MENASCHE, 2004, 2009). Esta revalorização dos "produtos naturais" envolve ainda um questionamento em relação à eficácia da medicina alopática, que pode ser relacionado a um processo histórico.

Fernandes (2004) aponta que, a partir da segunda metade do século XX, houve um aumento progressivo no uso de medicamentos sintéticos e industrializados, que passaram a prevalecer sobre o uso de plantas medicinais nas terapias modernas das sociedades ocidentais. Atualmente, assiste-se a uma redescoberta do potencial curativo das plantas medicinais, que são vistas como alternativas aos efeitos colaterais dos medicamentos industrializados e o seu elevado custo (FERNANDES, 2004; ADEODATO; OLIVEIRA; OLIVEIRA, 1996).

O terceiro ponto a ser destacado é que esta circulação de mercadorias entre imigrantes e os que permaneceram no país de origem fortalece as redes existentes e, ao mesmo tempo, cria novas relações. Neste sentido, a circulação participa de uma reconstrução social baseada em um espaço de expansão e mudança dos migrantes, assim como revela os modos de estruturação dos grupos no espaço. A integração dos migrantes para uma determinada área (geográfica, econômica e social), assim como a manutenção de suas relações com seu local de origem, ocorre através de modos de fornecimento específicos (LESDAIN, 2002).

A partir da teoria do dom, tal como formulada por Marcel Mauss, esta circulação de produtos entre brasileiros em Boston e no Brasil pode ser entendida como parte de um sistema de obrigações de dar, receber e retribuir (MAUSS, 2004). Desta forma, estes atos aparentemente voluntários são, de fato, obrigatórios, e sua dinâmica cria e fortalece 
relações sociais. ${ }^{7}$ Ao receberem e enviarem bens e produtos, os imigrantes fortalecem laços que os unem com os indivíduos de suas redes sociais que permaneceram em seu país de origem.

Estes fluxos de produtos também colocam em movimento valores e, por essa razão, podem ser considerados "remessas sociais", conceito criado pela socióloga estadunidense Peggy Levitt (1998). A autora define como "remessas sociais" as ideias, comportamentos, identidades e capital cultural que fluem da sociedade receptora para a sociedade de origem dos imigrantes (LEVITT, 1998). Neste sentido, através do fluxo de mercadorias circulam relações e lembranças que conectam indivíduos na Grande Boston com indivíduos em diversas localidades no Brasil. Quando utilizam os conhecimentos de suas mães e avós sobre plantas medicinais e outros cuidados com o corpo e tratamento de doenças, os imigrantes (re) conectam-se com sua memória familiar e/ou sua cultura de origem.

\section{A dinamicidade dos conhecimentos tradicionais}

Além de entender como estes medicamentos e plantas medicinais constituem formas de manutenção e fortalecimento de laços entre indivíduos, é também possível entender como os conhecimentos sobre os cuidados com o corpo e a saúde estão estritamente relacionados a processos socioculturais e históricos contemporâneos. Destaca-se, por exemplo, como estes medicamentos e plantas são utilizados para o tratamento de problemas relativos ao modo de vida urbano moderno, como a ansiedade e a depressão, como destacam os trechos dos depoimentos dos sujeitos da pesquisa transcritos abaixo.

Eu queria muito tomar alguma coisa pra ansiedade, porque eu sempre quero tudo pra ontem, sou muito ansiosa. Na última vez que fui pro Brasil, eu trouxe umas folhas de maracujá secas, pra fazer chá. Minha mãe usava muito para acalmar a gente... (Lúcia, 40 anos, vive na Holanda há sete anos).

\footnotetext{
${ }^{7}$ Na definição de Godbout, o dom é toda a prestação de bens ou serviços efetuada sem garantia de retribuição que tem o objetivo de criar ou alimentar laços sociais entre pessoas. Godbout destaca que o tempo está no centro do dom, pois através do retribuir religa-se o gesto do passado ao presente. $\mathrm{O}$ autor aponta ainda as características comuns do dom na sociedade moderna: a liberdade (grau de constrangimento apontado por Mauss parece desaparecido) e o caráter espontâneo (movimento de alma, não racionalidade do cálculo). $\mathrm{O}$ autor responde ainda que a ocultação do caráter obrigatório do dom é fundamental: quanto mais o gesto é percebido como incondicional, mais ele reforça o laço social. A explicitação da regra significa a morte do dom (GODBOUT, 1992).
} 
A minha avó costumava fazer um chá para animar o meu avô, que eu acho que tinha depressão. Naquela época, a gente não falava depressão, né? Só via a pessoa desanimada, triste, sem vontade para nada... Eu estava com depressão aqui, porque estou longe do meu filho, e de todo mundo. Aí eu perguntei para a minha mãe se ela lembrava do que era aquele chá que minha avó fazia para o meu avô. Ela disse que era de alecrim e de erva de são joão. $\mathrm{O}$ alecrim eu achei aqui no supermercado, e a erva de são joão eu pedi pra minha mãe mandar por correio. Eu tomo esses chás todos os dias, e me sinto um pouco melhor. (Iolanda, 33 anos, vive há cinco anos nos Estados Unidos).

Além da ansiedade e da depressão, os interlocutores da pesquisa também citaram o uso de plantas medicinais para emagrecimento. Neste sentido, é comum encontrar em seus depoimentos termos que caracterizam as propriedades terapêuticas destas plantas, como "diurética" e "termogênica", que, aliadas a dietas alimentares, são utilizadas para combater a gordura corporal. Fischler (1992) afirma que vive-se contemporaneamente em uma "sociedade lipofóbica" devido a esta busca por padrões de corpos magros e esguios. Nos trechos dos depoimentos de duas interlocutoras, é possível perceber como o fato de utilizar este uso contemporâneo do chá de carqueja está relacionado com os saberes dos antepassados dos sujeitos de pesquisa.

Minha mãe sempre tomava chá de carqueja e dizia que era bom pra digestão. Sempre fazia o chá depois de comer uma comida pesada. Eu não gostava de tomar porque era muito amarga. Hoje eu tomo para emagrecer. A minha mãe, os antigos, eles tinham muita sabedoria... eles estavam certos... Hoje a gente sabe que a carqueja é diurética e ajuda a emagrecer. Quando a minha irmã vem pra cá, ela sempre traz pra mim. Tem aqui também no mercado brasileiro, mas é muito caro (Fátima, 26 anos, vive nos Estados Unidos há nove anos).

A minha avó e o meu avó sempre diziam que a carqueja fazia bem, e que tinham que tomar o chá toda vez que comiam alguma coisa gordurosa. Eles eram bem magrinhos. Eu passei a tomar depois que li que era boa pra emagrecer. Aí eu lembrei da minha avó e do meu avô. Eles tinham carqueja no quintal da casa, eu lembro bem da planta. Quando eu vou no Brasil, sempre compro umas caixinhas pra trazer. Tomo quase todo dia. Eu ainda quero trazer uma mudinha pra tentar plantar aqui (Maria, 32 anos, vive há cinco anos em Amsterdam, na Holanda).

Para entender como estes saberes tradicionais dialogam com as práticas contemporâneas dos imigrantes, é necessário ressaltar o caráter dinâmico destes conhecimentos, que são constantemente reconstruídos e atualizados. De acordo com Cunha (2009, p.302), tanto a ciência quanto os saberes tradicionais são "formas de procurar entender e agir sobre o mundo. E ambos são também obras abertas, inacabadas, se fazendo constantemente". Para o senso comum, 
o conhecimento tradicional é um tesouro no sentido literal da palavra, um conjunto acabado que se deve preservar, um acervo fechado transmitido por antepassados e ao qual não se deve acrescentar nada. Nada é mais equivocado: o conhecimento tradicional consiste tanto ou mais em seus processos de investigação quanto nos acervos já prontos transmitidos pelas gerações anteriores. Processos. Modos de fazer. Outros protocolos (CUNHA, 2009, p. 302).

A obra do antropólogo britânico Tim Ingold também oferece contribuições para problematizar estes conhecimentos. Este antropólogo propõe que se dissolvam as diferenças entre ciências naturais e sociais, e propõe-se a investigar o conhecimento que as pessoas têm dos seus ambientes e as formas como se inserem nele. O autor faz uma crítica às separações entre corpo e mente, herança do pensamento cartesiano, e pensamento e prática, presente nas teorias das Ciências Humanas e Sociais. Ao invés de tentar entender as lógicas culturais que estariam por trás dos fatos, conforme as teorias culturalistas, Ingold parte da fenomenologia e da psicologia evolutiva (além de outras influências teóricas) para privilegiar o movimento e o engajamento dos seres vivos no ambiente.

Ingold critica o modelo genealógico de produção do conhecimento, no qual a herança genética ou cultural é passada de uma geração a outra. Deste modo, o conhecimento não constitui um conjunto herdado de fórmulas ou prescrições culturais, mas sim algo que se forma por meio de experiências de vida e trajetórias de movimento no ambiente. Ao invés de aplicar os conhecimentos na prática, argumenta Ingold, o processo de conhecimento ocorre através da prática. Para ele, fazer e conhecer estão interligados. Deste modo, os seres humanos adquirem habilidades na prática, ao invés de informações que são passadas de geração em geração.

Neste sentido, o conhecimento é baseado na construção de experiências e habilidades:

Trata-se do conhecimento que não é formal e autorizado, que pode ser transmitido em contextos fora de sua aplicação prática. Ao contrário, é baseado em sentimento, e consiste em habilidades, sensibilidades e orientações desenvolvidas através de longa experiência da condução da própria vida em um ambiente particular (Ingold, 2000, p. 25, tradução livre).

A prática foi constantemente apontada pelos sujeitos da pesquisa como ponto importante para a construção destes conhecimentos sobre os cuidados com o corpo. Os chás e remédios caseiros utilizados e/ou recomendados por suas mães, avós e outros familiares ou parentes são preparados, testados e, por vezes, adaptados pelos indivíduos. A partir 
destes usos, os sujeitos da pesquisa afirmaram continuar utilizando ou não estes recursos. Observação semelhante pode ser feita sobre o uso de medicamentos. Suas formas de utilização, dosagem e até mesmo sua combinação com outras formas de tratamento são verificadas pelos sujeitos por meio da experiência prática.

A gente só sabe se funciona quando usa. Se você toma um remédio, e continua com o problema, aí toma também um chá, às vezes tem que tomar mais algum comprimido... A gente tem que observar o que dá certo. Aí, quando fica doente de novo, você já sabe o que deu certo, e faz tudo direitinho (Sandra, 41 anos, vive na Holanda há quatro anos).

Quanto mais a gente usa os chás, mais a gente sabe sobre eles. Não tem jeito, você tem que experimentar. Foi assim com a minha avó, com a minha mãe, é assim comigo... Tem que ir testando. Eu usava chá de hibisco para perder uns quilinhos, para desinchar. Aí hoje eu alterno. Tem dia que eu tomo chá de hibisco, e tem dia que eu tomo chá verde, que eu aprendi nas revistas. Acho que está dando certo (Aparecida, 26 anos, vive nos Estados Unidos há oito anos).

Segundo Ingold (2010, p. 7), deve-se abandonar a dicotomia entre capacidades inatas e competências adquiridas, e considerar sistemas dinâmicos que atuam na produção de conhecimentos. De acordo com o autor, os seres humanos passam por um processo de habilitação, no sentido de formar habilidades, e não de enculturação. "No crescimento do conhecimento humano, a contribuição que cada geração dá à seguinte não é um suprimento acumulado de representações, mas uma educação da atenção" (INGOLD, 2010, p. 7).

Os seres humanos, de acordo com Ingold, aprendem por meio de um processo de habilitação, que se dá a partir das percepções. A geração predecessora contribui para o processo de aprendizagem da geração seguinte por meio da construção das condições do ambiente e do estabelecimento de determinadas tarefas. Ainda que os indivíduos busquem imitar a geração anterior, este processo de cópia através do qual ocorre o aprendizado é, para Ingold, um processo criativo dos sujeitos. Nas palavras do autor, a fonte desta criatividade não é a inovação, mas a improvisação (INGOLD, 2011), o que contribui para o constante aumento e renovação deste conhecimento nas práticas diárias dos sujeitos em movimento pelo mundo (INGOLD, 2010).

\footnotetext{
${ }^{8} \mathrm{O}$ processo de endoculturação, que compreende a dinâmica cultural na qual os conhecimentos são acumulados e transmitidos entre gerações, é considerado por autores como Viertler (1988) como responsável pela continuidade dos conhecimentos tradicional.
} 
As observações de Ingold podem ser úteis para entender como os imigrantes mantêm ou modificam seus hábitos cotidianos, como os cuidados com o corpo por meio de plantas medicinais. Através de habilidades que desenvolvem ao longo de suas vidas, baseadas em experiências e percepções, buscam aquilo que consideram necessário para resolver seus problemas de saúde ou da estética corporal. Assim, apropriam-se do conhecimento tradicional, de suas mães e avós, mas também renovam este conhecimento, colocando-o em movimento, ao longo de suas próprias trajetórias.

\section{Considerações finais}

Os fluxos de medicamentos, plantas medicinais e saberes relacionados aos cuidados com o corpo podem oferecer possibilidades de entendimento de processos socioculturais complexos. Neste texto, afirma-se que este fluxo (entre outras formas de circulação de bens) carregam também valores e ideias conectadas a indivíduos e grupos sociais, e podem servir como meios para fortalecer e manter laços entre sujeitos em dois contextos distintos.

Por outro lado, os dados de campo também revelam como os conhecimentos sobre as plantas medicinais, que os imigrantes atribuem a suas mães e avós, devem ser entendidos a partir de seu caráter dinâmico, pois dialogam com outras informações e, por vezes, adquirem vocabulário biomédico, atualizando suas formas tradicionais de uso para contemplar os cuidados daquilo que afeta os indivíduos, como ansiedade e depressão, e a luta pelo emagrecimento.

Ainda que não se tenha aqui o objetivo de estender estas conclusões a outros contextos ou grupos migratórios, nem de esgotar as possibilidades de análise destes fluxos, estas teorias permitem entender este fenômeno complexo a partir de suas dimensões microssociais, ou seja, atentar para as formas como os sujeitos vivenciam o cotidiano e se engajam em um contexto sociocultural distinto de sua sociedade de origem.

\section{Referências}


ADEODADO, S.; OLIVEIRA, L.; OLIVEIRA, V. Uma farmácia no fundo do quintal. São Paulo: Globo, 1996.

ANTHIAS, F. Metaphors of Home: Gendering New Migrations to Southern Europe. In: ANTHIAS, F., LAZARIDIS, G. Gender and Migration in Southern Europe: Women on the move. New York: Berg, 2001. p. 15-47

ASSUNÇÃO, V. K. Circulating Food and Relationships: the Movement of Food (and Other Things) Between Brazilians in Boston and Brazil. International Review of Social Research, v. 2, p. 63-74, 2012.

ASSUNÇÃO, V. K. Etnografando o consumo alimentar: reflexões sobre trabalho de campo, viagem e afetos. In: GOIDANICH, M. E.; MEZABARBA, S. R. (Org.). Etnografias possíveis: Experiências etnográficas sobre consumo no ambiente urbano. 01ed.Rio de Janeiro: Ponteio, 2014, v. 01, p. 41-66.

BASTIDE, R. La causalité externe et la causalité interne dans l'explication sociologique. Cahiers internationaux de sociologie, n. 21, 1956, p. 77-99.

BOYD, M. Family and personal networks in international migration: recent developments and new agenda. International Migration Review, Vol. 23, n. 3, p. 638-670, 1989.

CARDOSO DE OLIVEIRA, R. O Trabalho do Antropólogo. Brasília/São Paulo: Paralelo Quinze/Editora da Unesp, 1998.

CLIFFORD, J. Introduction: Partial truths. In: CLIFFORD, J., MARCUS, G. (ed.). Writing Culture. Berkeley, CA: University of Califórnia, 1986. p. 1-26

CUNHA, M. C. Cultura com Aspas e outros ensaios. São Paulo: Cosac Naify, 2009.

FERNANDES, T.M.D. Plantas medicinais: memória da ciência no Brasil. Rio de Janeiro: Fiocruz, 2004.

FISCHLER, C. L'Homnivore. Paris, Odile Jacob: 1992.

GODBOUT, Jacques. O espírito da dádiva. Lisboa, Instituto Piaget, 1992.

GONÇALVES, A. M. A mulher que cuida do doente mental em família. 1999. Dissertação (Mestrado em Educação) - Faculdade de Educação, Universidade Federal de Minas Gerais, Belo Horizonte, 1999.

INGOLD, T. The perception of the environment. Londres: Routledge, 2000.

. Da transmissão de representações à educação da atenção. Educação, Porto Alegre, v. 33, n. 1, p. 6-25, jan./abr. 2010. 
.Making growing learning. (2011) Disponível em: https://www.ufmg.br/ieat/wpcontent/uploads/2015/06/Tim-Ingold-Making-Growing-Learning1.pdf. Acesso em: 15 ago. 2015.

LESDAIN, S. B. Alimentation et migration, une définition spatiale. In: GARABUAUMOUSSAOUI, I., PALOMARE, E., DESJEUX, D. (ed.). Alimentations contemporaines. Paris: L’Harmattan, 2002. p. 173-189

LEVITT, P. Social Remittances: Migration Driven Local-Level Forms of Cultural Diffusion. International Migration Review. Vol. 32, N. 04, p. 926-948, 1998.

MASSEY, D. The social organization of migration. In: MASSEY, D., ALARCON, R., DURAND, J., GONZÁLEZ, H. (ed.). Return to Aztlan: the social process of international migration from Western Mexico. Berkeley, University of California Press, 1990. p.139-171

MAUSS, M. Ensaio sobre a dádiva: forma e razão da troca nas sociedades arcaicas". In: MAUSS, M. Sociologia e Antropologia. São Paulo: Cosac \& Naify, [1925] 2004. p. 183314

MENASCHE, R. Countryside and the City, Food and the Imaginary: Perceptions of the Rural at the Table. Estudios del Hombre: Serie Antropología de la Alimentación, Guadalajara, n. 24, 2009. p. 255-268

. Riscos à mesa: alimentos transgênicos no meu prato não? Campos: Revista de Antropologia Social, Curitiba, v. 5, n. 1, p.111-129, 2004.

MOREIRA, M. C. N. Imagens no espelho de Vênus: mulher, enfermagem e modernidade. Revista Latino Americana de Enfermagem, v.7, n.1, p.55-65, jan.1999.

PEIRANO, M. A Favor da Etnografia. Rio de Janeiro, Relume-Dumará, 1995.

PEGORARO, R. F. Familiares que cuidam de portadores de sofrimento mental: histórias de dor, vidas de sofrimento. 2002. Dissertação (Mestrado em Psicologia) - Faculdade de Filosofia, Ciências e Letras de Ribeirão Preto, Universidade de São Paulo, Ribeirão Preto, 2002.

PEGORARO, R. F.; CALDANA, R. H. L. Sobrecarga de familiares de usuários de um Centro de Atenção Psicossocial. Psicologia em Estudo, Maringá, v. 11, n. 3, p. 569-577, set./dez. 2006.

ROSA, L. C. S. Transtorno mental e o cuidado na família. São Paulo: Cortez, 2003.

SIMMEL, Georg, A natureza sociológica do conflito. In: MORAES FILHO, Evaristo (org.). 
Revista Tecnologia e Ambiente, v. 21, n.1, 2015, Criciúma, Santa Catarina. ISSN: 1413-8131 (versão impressa) ISSN: 2358-9426 (versão eletrônica)

Simmel. São Paulo: Ática, 1983.

VIERTLER, R. B. Ecologia cultural: uma antropologia da mudança. São Paulo: Ática, 1988. 